members of the general population who had not competed at an Olympic Games.

Interventions (or Assessment of Risk Factors) Recruitment of participants took place over a 14-month period (Apr 2018May 2019), during which an electronic survey was distributed, in eight languages, by email and social media through World Olympians Association and International Olympic Committee channels. Platforms included Olympians.org, National Olympians Associations, National Olympic Committees, International Federations, Athlete 365 and Olympic Studies Centre. Control recruitment also involved Olympian 'buddies', and regional leisure, medical and community centres.

Main Outcome Measurements Number and distribution of Olympian and control participants.

Results There were 4,745 Olympian and 2,462 control online survey entries. Data cleaning removed 1,388 Olympian and 727 control ineligible entries (e.g. blank, duplicate, incomplete, under-16 yrs) leaving 3,357 Olympian (age 16-97) and 1,735 control (age 16-88) completed questionnaires, from 131 and 73 Countries (respectively) eligible for data analysis.

Conclusions The distribution of Olympians and controls recruited to the study, and recording of lifetime injury history, sport and exercise exposure and general health measures, will allow analyses of risk factors associated with Olympic-career injury and current health status.

\section{PREVENTING HEAT STRESS BEFORE THE TOKYO OLYMPIC GAMES, THE CASE OF OPEN WATER}

${ }^{1}$ Robin Pla, ${ }^{2}$ Anaël Aubry. ${ }^{1}$ French Swimming Federation, Clichy, France; ${ }^{2}$ Vital ConceptBandB Hotels Cycling Team, Loudéac, France

\subsection{6/bjsports-2021-IOC.174}

Background A huge heat stress is expected during the Tokyo 2020 Olympic Games, especially for the open-water swimming event. Literature is scarce about the physiological responses to open-water swimming events in warm water.

Objective The purpose of this study was to collect data from Tokyo's thermal environment one year before the Olympic Games and to observe the physiological responses of swimmers participating in the test event.

Design Individual deep body temperatures were collected before, during and after an open-water $5-\mathrm{km}$ race. Thermal environment was also collected. After the race, a simple questionnaire was administrated to the swimmers, to evaluate their perceived heat stress.

Setting The study took place during the open-water swimming Olympic test event in Tokyo.

Patients (or Participants) Three world-class open-water swimmers (two males and two females) participated in the study. All were selected by the french swimming federation.

Interventions (or Assessment of Risk Factors) Some pre-cooling strategies were used before the race as wearing cooling jacket, drinking cold beverages, putting a wet towel on the neck.

Main Outcome Measurements The main outcome of the study was to report the individual temperature regulation in order to prevent hyperthermia syndrome for the next Summer Olympic Games.

Results At the end of the race (8:00 AM), the water temperature was $30.3^{\circ} \mathrm{C}$ and the relative humidity was $61.1 \%$. Individual body temperatures were $39.2^{\circ} \mathrm{C}, 39.5^{\circ} \mathrm{C}$ and $39.7^{\circ} \mathrm{C}$ whereas the average body temperature at the beginning of the race was $37.2^{\circ} \mathrm{C}$. The survey findings indicate that swimmers perceived a high to very high heat stress during the race.

Conclusions The Olympic organizing committee should consider these results to better avoid hyperthermia on open-water swimmers, in determining the timings on the events. The swimmers and background staffs need to use appropriate heat acclimatization strategies to reduce the risk of heat illness and to maximize swimming performance.

\section{REFEREES CAN PREVENT INJURIES IN WRESTLING; AN EXPERIENCE FROM THE 2018 YOUTH OLYMPIC GAMES}

\footnotetext{
1,2Babak Shadgan, 'Loukas Konstantinou, 'Szabolcs Molnar. 'UWW Medical, Prevention and Anti-Doping Commission, Corsier-sur-Vevey, Switzerland; '2University of British Columbia, Department of Orthopaedics, Vancouver, Canada
}

\subsection{6/bjsports-2021-IOC.175}

Background Olympic wrestling styles can result in various types of soft tissue and musculoskeletal injuries. Head and face skin contusions and lacerations were the most common type of injuries, followed by ligament sprains, muscle strains and upper limb joint subluxations and dislocations. The main mechanisms of injuries are direct trauma, using legs and arms as levers, falling, and twisting; most injuries happen during the standing position when two wrestlers engage for a takedown and collide with their heads and limbs. It's while performing dangerous actions and some high-risk manoeuvres are forbidden based on current regulations of the United World Wrestling. Recognizing and stopping dangerous actions during wrestling competitions are the responsibility of the referee. We hypothesized that a prompt and proper action of referees to stop dangerous actions and faults could reduce the incidence and severity of wrestling injuries.

Objective To study the potential effect of a proactive and cautious referee practice on reducing the rate and severity of wrestling injuries during international level junior championships.

Design Prospective observational study.

Setting Competitive world-level junior wrestlers.

Participants 768 Junior wrestlers.

Interventions Wrestling referees of 2018 Youth Olympic Games that was held on October 2018 in Buenos Aires were instructed to be extremely careful, prompt and proactive in stopping high-risk and dangerous actions. Data and specifications of injuries among 110 participant wrestlers in 2018 Youth Olympic Games have compared with injuries occurred among 658 wrestlers who competed at 2018 Junior World Championships on September 2018 in Trnava/Slovakia governed by a routine referee practice.

Main outcome measurements Rate, severity, type, location and mechanism of injuries.

Results Rate of wrestling injuries during 2018 Junior world championships and the 2018 Youth Olympic Games were $10.64 \%$ and $4.54 \%$ respectively.

Conclusions Proactive and cautious actions of wrestling referees to promptly stop dangerous actions has the potential to significantly reduce the rate and severity of injuries in wrestling. 